\title{
Synthesis of Core-Shell Nanoparticles of Cu-Ag for Application in Electrohydrodynamic Printing Technique
}

\author{
Chinh Dung Trinh ${ }^{1,2}$, Dung My Thi Dang ${ }^{1}$ and Chien Mau Dang ${ }^{1}$ \\ 1. Institute for Nanotechnology, Vietnam National University, Ho Chi Minh City 800010, Vietnam \\ 2. The University of Science, Vietnam National University, Ho Chi Minh City 800010, Vietnam
}

\begin{abstract}
Core-shell nanoparticles of $\mathrm{Cu}-\mathrm{Ag}$ (Cu core and $\mathrm{Ag}$ shell) were synthesized using chemical method. Polyvinyl pyrrolidone (PVP) was used as a surfactant, and ascorbic acid $\left(\mathrm{C}_{6} \mathrm{H}_{8} \mathrm{O}_{6}\right)$ and sodium borohydride $\left(\mathrm{NaBH}_{4}\right)$ were used as reducing agents to reduce the metal complexes $\left[\mathrm{Cu}\left(\mathrm{NH}_{3}\right)_{4}\right]^{2+}$ and $\left[\mathrm{Ag}\left(\mathrm{NH}_{3}\right)_{2}\right]^{+}$. The results of transmission electron microscope (TEM) analysis, ultraviolet-visible spectroscopic (UV-Vis) analysis, X-ray diffraction (XRD) analysis showed that the core-shell nanoparticles of $\mathrm{Cu}-\mathrm{Ag}$ were successfully synthersized. The average particle size was $32 \mathrm{~nm}$. The dispersion of the nanoparticles was still good after 80 days without the formation of the oxides of $\mathrm{Cu}$ and $\mathrm{Ag}$. The properties of the nanoparticles suggested that they were suitable to be used as an electrically conductive material for conductive ink-jet printing inks.
\end{abstract}

Key words: Nanoparticles, nano bimetal, Ag nanoparticles.

\section{Introduction}

In the recent years, the ink-jet printing technique has become popular with many applications [1]. Ink-jet printing provides excellent resolution on paper and many other materials. The recent reports suggested that ink-jet printing could be used to fabricate the thin membranes [2]. One of the advantages of this technique is that it can be used to fabricate the membranes without the need of mask. Thus, it provides excellent application potential in fabrication of microelectronic boards on plastic substrates. The printing methods include: offset printing, printing with the aid of sun light, printing using soft mold, and ink-jet printing. All of these methods provide similar resolution, about 10-30 $\mu \mathrm{m}$. The advantage of ink-jet printing compared to other methods is no need of mask. A computer will control to print each dot based on a designed image, giving quick printing at low cost. The ink-jet printing techniques include: piezoelectric ink-jet printing,

Corresponding author: Dung My Thi Dang, Dr., research fields: inkjet printing, nanomaterials. buble jet ink-jet printing, and aerosol ink-jet printing. They work by pressing ink through a small hole (micrometer size or smaller) to produce very small ink droplets on substrate. Ink-jet printing technique can be used to print on every material from paper, metal, semiconductor to plastics.

The inks for ink-jet printing are normally fabricated based on functional nanoparticles such as $\mathrm{Au}, \mathrm{Ag}$, or rare earth. In the ink-jet printing technology, research of fabrication of inks based on the functional nanoparticles is very important because it directly relates to properties and application purposes of products after printing.

$\mathrm{Ag}$ nanoparticles possess many advantages for fabrication of conductive inks, because the electrical conductivity of $\mathrm{Ag}$ is the best among metals and it is also difficult to be oxidized in normal conditions [3, 4]. However, because of the high cost of $\mathrm{Ag}$, the conductive inks based on $\mathrm{Ag}$ nanoparticles will be very expensive, making them difficult to be used in the industrial applications. Because of this reason, we attempt to reduce the content of $\mathrm{Ag}$ in the inks without sacrificing their electrical conductivity by fabrication 
of conductive inks based on core-shell nanoparticles with $\mathrm{Cu}$ core and $\mathrm{Ag}$ shell instead of using $\mathrm{Ag}$ nanoparticles. We expect that the fabrication of conductive inks using the $\mathrm{Cu}-\mathrm{Ag}$ core-shell nanoparticles will help to reduce a significant amount of $\mathrm{Ag}$, because the cores of the nanoparticles are $\mathrm{Cu}$ having low cost. The $\mathrm{Cu}-\mathrm{Ag}$ core-shell nanoparticles will be expected to have similar electrical conductivity compared to $\mathrm{Ag}$ nanoparticles, because the shells of the core-shell nanoparticles are Ag. In this paper, we present the method for synthesis of the $\mathrm{Cu}-\mathrm{Ag}$ core-shell nanoparticles for fabrication of conductive inks for ink-jet printing.

\section{Experimental Setup}

\subsection{Materials}

Silver nitrate $\left(\mathrm{AgNO}_{3}\right)$ (Merck), copper (II) sulfate $\left(\mathrm{CuSO}_{4} \cdot 5 \mathrm{H}_{2} \mathrm{O}\right)$ (Merck), ascorbic acid $\left(\mathrm{C}_{6} \mathrm{H}_{8} \mathrm{O}_{6}\right)$ (Merck), sodium borohydride $\left(\mathrm{NaBH}_{4}\right)$ (Merck), polyvinylpyrrolidone $40000\left(\mathrm{C}_{6} \mathrm{H}_{9} \mathrm{NO}\right)_{\mathrm{n}}(\mathrm{BASF})$ were used as received.

\subsection{Synthesis Method and Measurement}

\subsubsection{Synthesis Method}

PVP and ascorbic acid were dissolved in deionization (DI) water to obtain PVP solution $(0.0015 \mathrm{M})$ and ascorbic acid solution $(0.1 \mathrm{M})$. After that, the two solutions were mixed using magnetic stirrer. $\mathrm{CuSO}_{4}$ solution $(0.05 \mathrm{M})$ was then added dropwise to the above solution followed by adding $\mathrm{NaBH}_{4}$ solution. After 10 minutes, $\mathrm{AgNO}_{3}$ solution $(0.05 \mathrm{M})$ was added dropwise to the above solution. Temperature of the solution was kept constantly at 50 ${ }^{\circ} \mathrm{C}$ in all steps.

\subsubsection{Measurement}

The obtained core-shell nanoparticles were characterized using X-ray diffractometer (XRD), ultraviolet-visible spectrometer (UV-Vis) (Cary 100), transmission electron microscope (TEM) (JEM model $1400,100 \mathrm{kV})$. Particle size distribution was obtained using ImageJ software.

\section{Experimental Results}

3.1 Effects of $\mathrm{NaBH}_{4}$ Reducing Agent on the Formation of Cu-Ag Core-Shell Nanoparticles

In this work, $\mathrm{Cu}-\mathrm{Ag}$ core-shell nanoparticles having particle size of around 40 nanometer were synthesized using chemical reduction method. The reactions are presented as followed [5-7]:

$$
\begin{aligned}
& 2 \mathrm{Ag}^{+}+\mathrm{C}_{6} \mathrm{H}_{8} \mathrm{O}_{6}=2 \mathrm{Ag}^{0}+\mathrm{C}_{6} \mathrm{H}_{6} \mathrm{O}_{6}+2 \mathrm{H}^{+} \\
& \mathrm{Cu}^{2+}+\mathrm{C}_{6} \mathrm{H}_{8} \mathrm{O}_{6}=\mathrm{Cu}^{0}+\mathrm{C}_{6} \mathrm{H}_{6} \mathrm{O}_{6}+2 \mathrm{H}^{+} \\
& \mathrm{Ag}^{+}+\mathrm{BH}_{4}^{-}+3 \mathrm{H}_{2} \mathrm{O}=\mathrm{Ag}^{0}+\mathrm{B}(\mathrm{OH})_{3}+3.5 \mathrm{H}_{2}(3) \\
& \mathrm{Cu}^{2+}+2 \mathrm{BH}_{4}^{-}+6 \mathrm{H}_{2} \mathrm{O}=\mathrm{Cu}^{0}+7 \mathrm{H}_{2}+2 \mathrm{~B}(\mathrm{OH})_{3}(4) \\
& \mathrm{Cu}^{0}+2 \mathrm{Ag}=2 \mathrm{Ag}^{0}+\mathrm{Cu}^{2+}
\end{aligned}
$$

In this synthesis method, the metal salts of $\mathrm{CuSO}_{4}$ and $\mathrm{AgNO}_{3}$ were treated with $\mathrm{NH}_{4} \mathrm{OH}$ to obtain the metal complexes of $\left[\mathrm{Cu}\left(\mathrm{NH}_{3}\right)_{4}\right]^{2+}$ and $\left[\mathrm{Ag}\left(\mathrm{NH}_{3}\right)_{2}\right]^{+}$ followed by reducing to metallic $\mathrm{Cu}^{0}$ and $\mathrm{Ag}^{0}$. Fig. 1 shows the development steps of the $\mathrm{Cu}-\mathrm{Ag}$ core-shell nanoparticles.

To investigate the effects of $\mathrm{NaBH}_{4}$ reducing agent on the formation of $\mathrm{Cu}-\mathrm{Ag}$ core-shell nanoparticles, the samples $\mathrm{a}, \mathrm{b}, \mathrm{c}$ were prepared with variation of volume ratio of $\mathrm{NaBH}_{4} / \mathrm{Cu}^{2+}=R(R=0.5,1,2)$. Concentration and ratio of other chemicals were kept constant as in Table 1.

Fig. 2 shows that the UV-Vis spectra of samples a and $\mathrm{c}$ exhibit only one peak at $415 \mathrm{~nm}$ (surface plasmon resonance of spherical Ag nanoparticles), suggesting the presence of $\mathrm{Ag}$ nanoparticles in the solution but without the presence of $\mathrm{Cu}$ nanoparticles. The spectrum of sample $b$ exhibits a broad band from

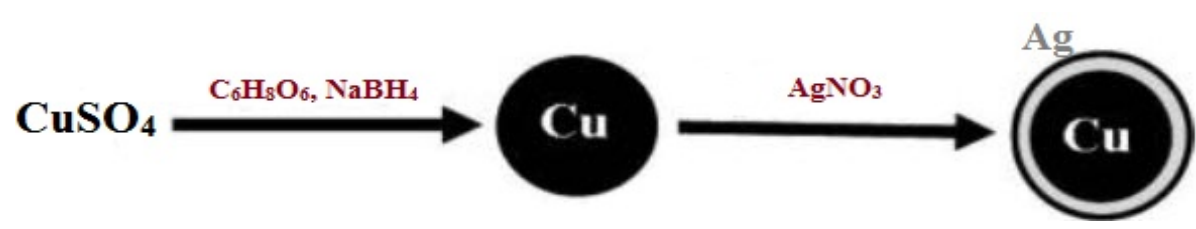

Fig. 1 The development steps of $\mathrm{Cu}$-Ag core-shell nanoparticles. 
Table 1 The samples with the ratio of the reactants in the Ag nanoparticles preparation reactions.

\begin{tabular}{lllll}
\hline Samples & $\mathrm{Ag}^{+} / \mathrm{Cu}^{2+}$ & $\mathrm{Cu}^{2+} / \mathrm{C}_{6} \mathrm{H}_{8} \mathrm{O}_{6}$ & $\mathrm{Cu}^{2+} / \mathrm{PVP}$ & $\mathrm{NaBH}_{4} / \mathrm{Cu}^{2+}$ \\
\hline $\mathrm{a}$ & 0.2 & 0.2 & 0.02 & 0.5 \\
$\mathrm{~b}$ & 0.2 & 0.2 & 0.02 & 1 \\
$\mathrm{c}$ & 0.2 & 0.2 & 0.02 & 2 \\
\hline
\end{tabular}

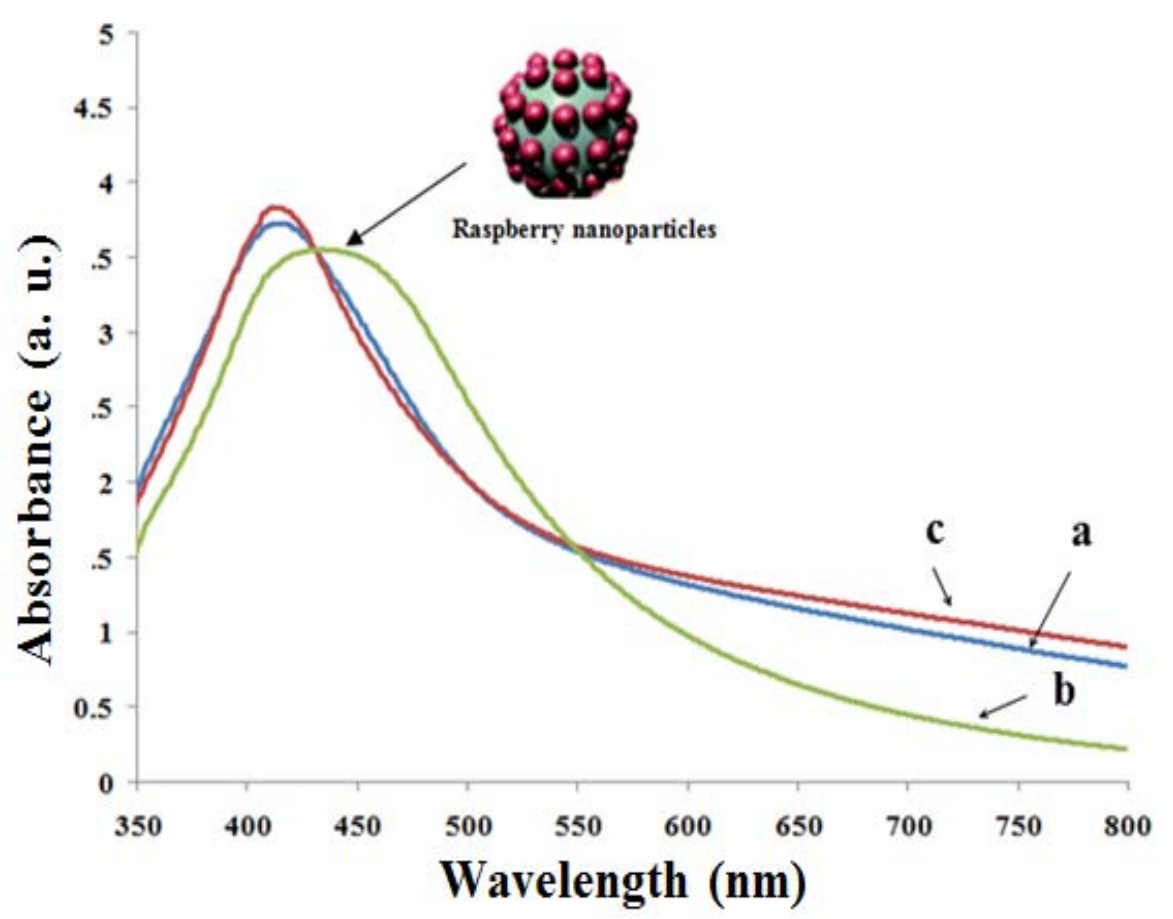

Fig. $2 \mathrm{UV}$-Vis spectra of the samples synthesized with different volume ratio of $\mathrm{NaBH}_{4} / \mathrm{Cu}^{2+}$.

$415 \mathrm{~nm}$ to $460 \mathrm{~nm}$. This kind of UV-Vis spectrum suggests the presence of bimetallic raspberry nanoparticles [8]. A bimetallic raspberry nanoparticle is a structure in which a metal nanoparticle served as a core is covered by nanoparticles of another metal, but not fully covered. The plasmon resonance peak of $\mathrm{Cu}$ nanoparticles appeared at a longer position $(\sim 530 \mathrm{~nm})$ compared to that of Ag nanoparticles. This may be the reason for the broadening of the peak of the spectrum. The results suggest that, with sample a, the amount of $\mathrm{NaBH}_{4}$ was not enough to reduce $\mathrm{Cu}^{2+}$ to metallic $\mathrm{Cu}$. With sample c, a great amount of reducing agents may cause a quick oxidation of the surface of the $\mathrm{Cu}$ nanoparticles. These resulted in the absence of the peak of $\mathrm{Cu}$ nanoparticles in the spectra of the two samples a and c.

\subsection{Effects of $\mathrm{Ag}^{+} / \mathrm{Cu}^{2+}$ Ratio on the Formation of $\mathrm{Cu}$-Ag Core-Shell Nanoparticles}

To investigate the effects of ratio of $\mathrm{Ag}^{+} / \mathrm{Cu}^{2+}=L$ on the formation of $\mathrm{Cu}-\mathrm{Ag}$ core-shell nanoparticles, the samples were synthesized with $L=0.2,0.4,0.6$, 0.8 . The ratio of other chemicals was kept constant and $R=1$.

Fig. 3 shows the UV-Vis spectra of the samples synthesized with different ratio of $\mathrm{Ag}^{+} / \mathrm{Cu}^{2+}$. Inset is the spectrum of $\mathrm{Cu}-\mathrm{Ag}$ nanoparticles reported by Tsail et al. [9]. As seen in Fig. 3, the spectra of the samples with $L=0.2$ and 0.4 exhibit two peaks at $\sim 400 \mathrm{~nm}$ (peak 1) and 525-535 nm (peak 2). These two peaks correspond to the absorption regions of $\mathrm{Ag}$ nanoparticles (peak 1) and $\mathrm{Cu}$ nanoparticles (peak 2). 


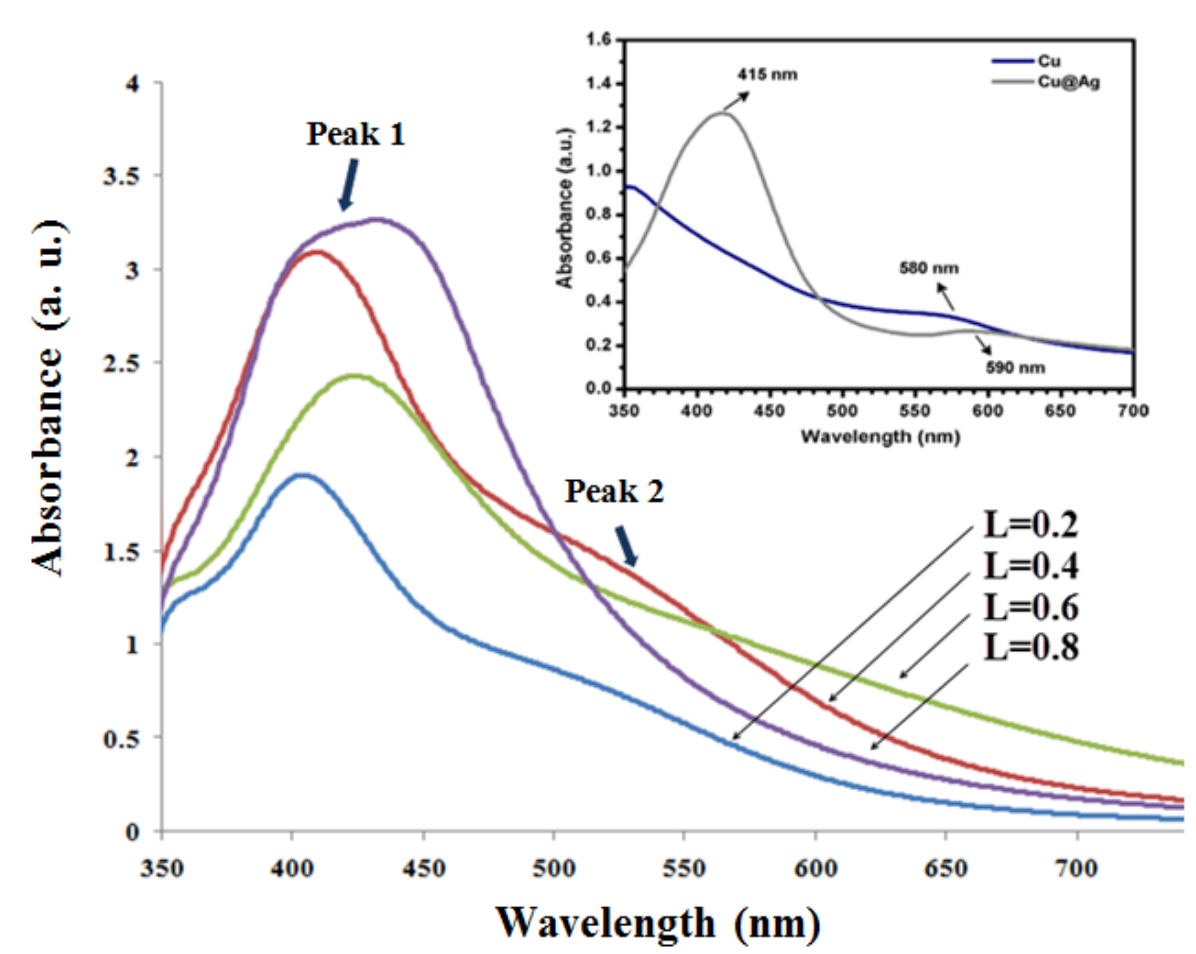

Fig. $3 \mathrm{UV}$-Vis spectra of the samples synthesized with different ratio of $\mathrm{Ag}^{+} / \mathrm{Cu}^{2+}$. Inset is the spectrum of $\mathrm{Cu}-\mathrm{Ag}$ nanoparticles reported by Tsail et al. [9].

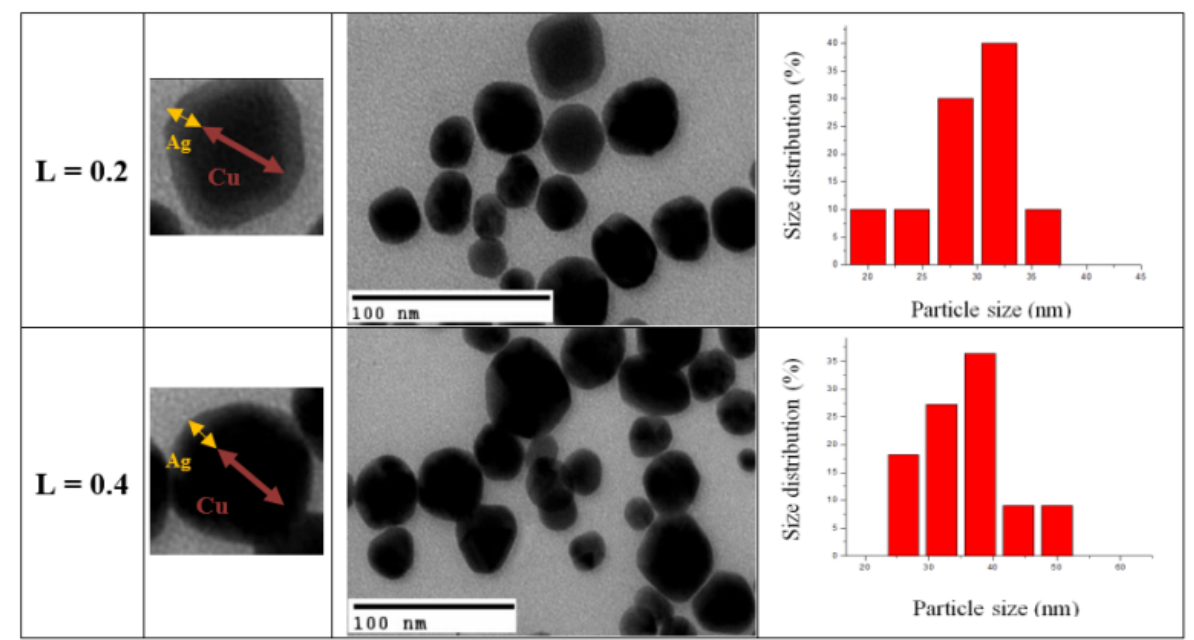

Fig. 4 TEM images and particle size distributions of the samples synthesized with different ratio of $\mathrm{Ag}^{+} / \mathrm{Cu}^{2+}$.

The spectra of the samples are similar to the spectrum of $\mathrm{Cu}-\mathrm{Ag}$ nanoparticles reported by Tsail et al. [9]. The spectra of the samples with $L=0.6$ and 0.8 exhibit only one peak at the absorption region of $\mathrm{Ag}$ nanoparticles ( 420-432 nm), suggesting the absence of $\mathrm{Cu}$ nanoparticles in the samples. The absorption intensity at $\sim 400 \mathrm{~nm}$ of the sample with $L=0.4$ is higher than that of the sample with $L=0.2$, indicating a higher density of Ag nanoparticles.

Fig. 4 shows the TEM images and particle size distributions of the samples with $L=0.2$ and 0.4 , indicating the presence of core-shell nanoparticles in both samples. From the results of UV-Vis absorption (Fig. 3), it can be concluded that these core-shell nanoparticles are $\mathrm{Cu}-\mathrm{Ag}$ core-shell nanoparticles. The sample with $L=0.2$ has average particle size of about 
$32 \mathrm{~nm}$, while the sample with $L=0.4$ has average particle size of about $40 \mathrm{~nm}$. This shows that when the volume of $\mathrm{Ag}^{+}$solution increased, the particle size tends to increase. It may relate to reaction (5), because when the volume of $\mathrm{Ag}^{+}$solution increased, the amount of $\mathrm{Cu}^{2+}$ also increased, and they were reduced by the reducing agents in the solution that caused the particle size increased [8].

\subsection{Effects of $p H$ on the Formation and Stability of Cu-Ag Core-Shell Nanoparticles}

Metal nanoparticles dispersed in a solution always have a surface electric charge to avoid aggregation [10]. The mechanism for the formation of electric charge depends on the properties of the metal nanoparticles and the solvent. In this method, we used DI water as solvent, thus the surface electric charge of the metal nanoparticles will be affected by the $\mathrm{pH}$ of the solution (Nernst equation). Therefore, the $\mathrm{pH}$ of the solution will affect the dispersion or the aggregation of the metal nanoparticles. We synthesized the samples with $L=0.4$ and with $\mathrm{pH}=2$,
$4,6,8,10$.

Fig. 5 shows that, with $\mathrm{pH}=6$, the UV-Vis spectrum is similar to the results reported for $\mathrm{Cu}-\mathrm{Ag}$ nanoparticles. The spectrum exhibits two peaks corresponded to $\mathrm{Ag}$ nanoparticles at $\sim 400 \mathrm{~nm}$ and $\mathrm{Cu}$ nanoparticles at $\sim 530 \mathrm{~nm}$. The spectra of other samples are not clear with broad peaks. The spectrum of sample with $\mathrm{pH}=2$ exhibits no peak. The color of the solutions of the samples was also varried and tended to darken when the $\mathrm{pH}$ increased. Observation of the samples after 10 days from synthesis showed that the sample with $\mathrm{pH}=6$ had no agglomeration. The samples with $\mathrm{pH}=8,10$ slightly aggregated, and the color of the solutions was unchanged. The samples with $\mathrm{pH}=2,4$ heavily aggregated, and the color of the solutions became lighter. Thus, with $\mathrm{pH}=6$, the $\mathrm{Cu}-\mathrm{Ag}$ core-shell nanoparticles were formed and stably dispersed in the solution after 10 days from synthesis. However, the stability of the sample in a longer time needs to be further investigated, because it is very important for application of the $\mathrm{Cu}-\mathrm{Ag}$ core-shell nanoparticles for fabrication of conductive inks.

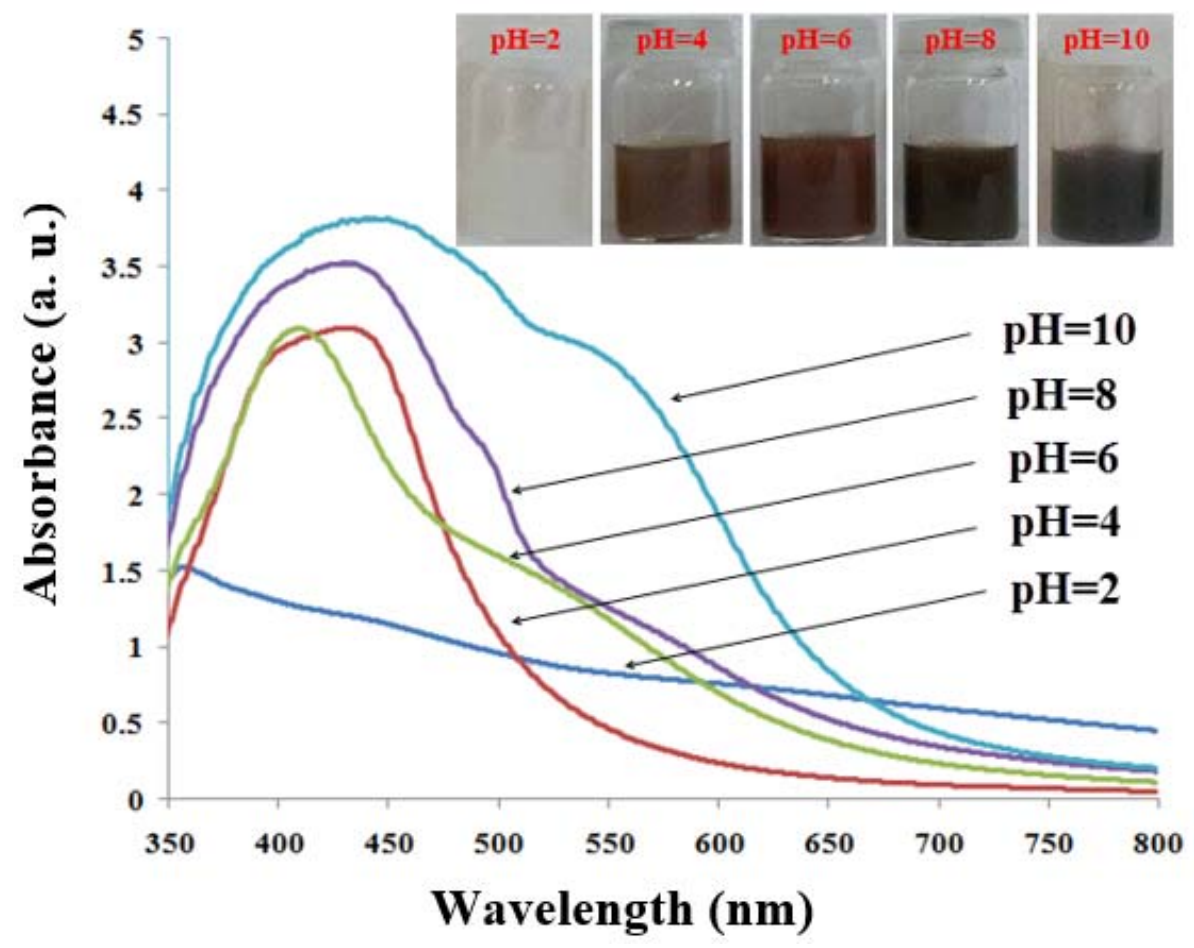

Fig. 5 UV-Vis spectra and photographs of the samples synthesized with $\mathrm{pH}=2,4,6,8,10$. 


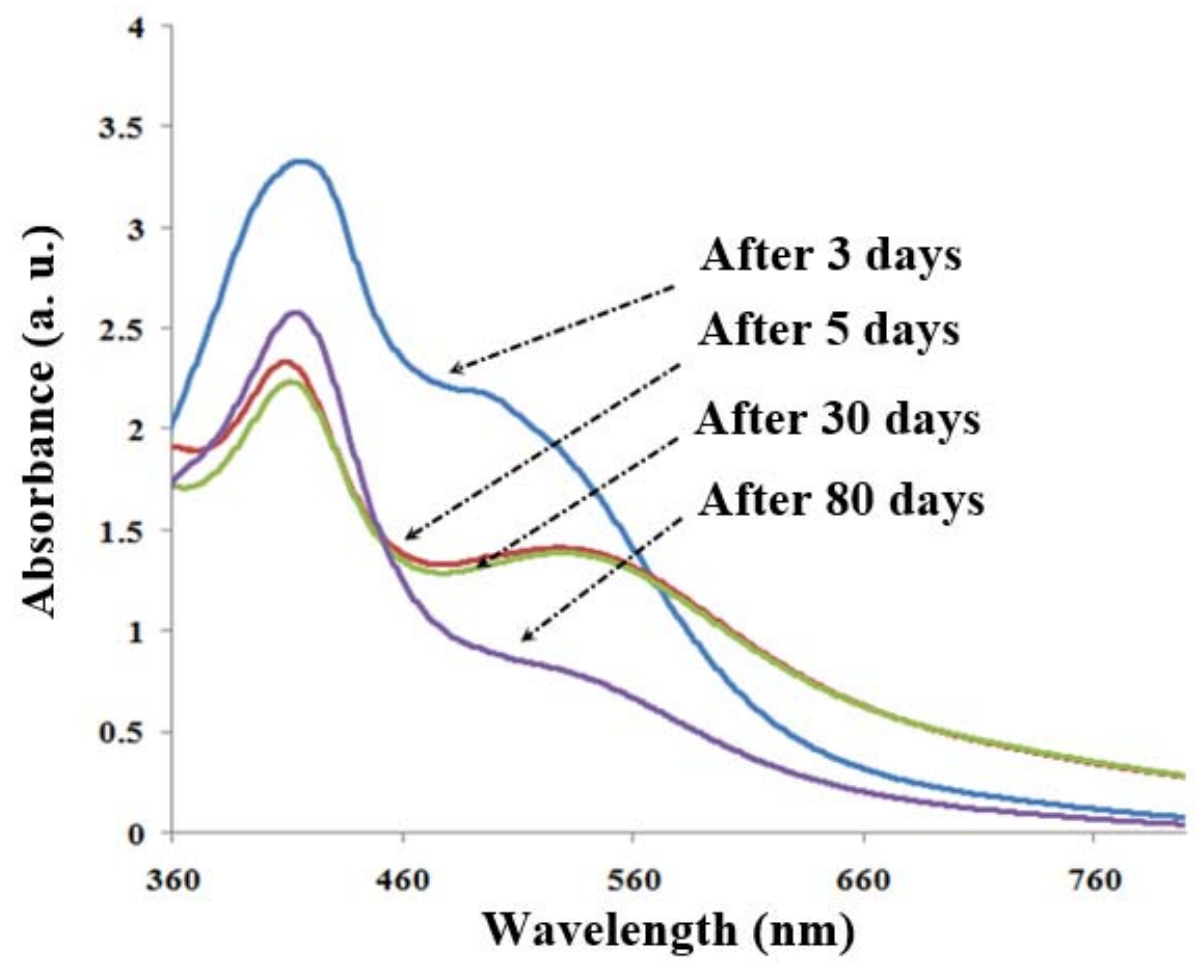

Fig. 6 UV-Vis spectra of the sample with $\mathrm{pH}=6$ measured after different time from synthesis.

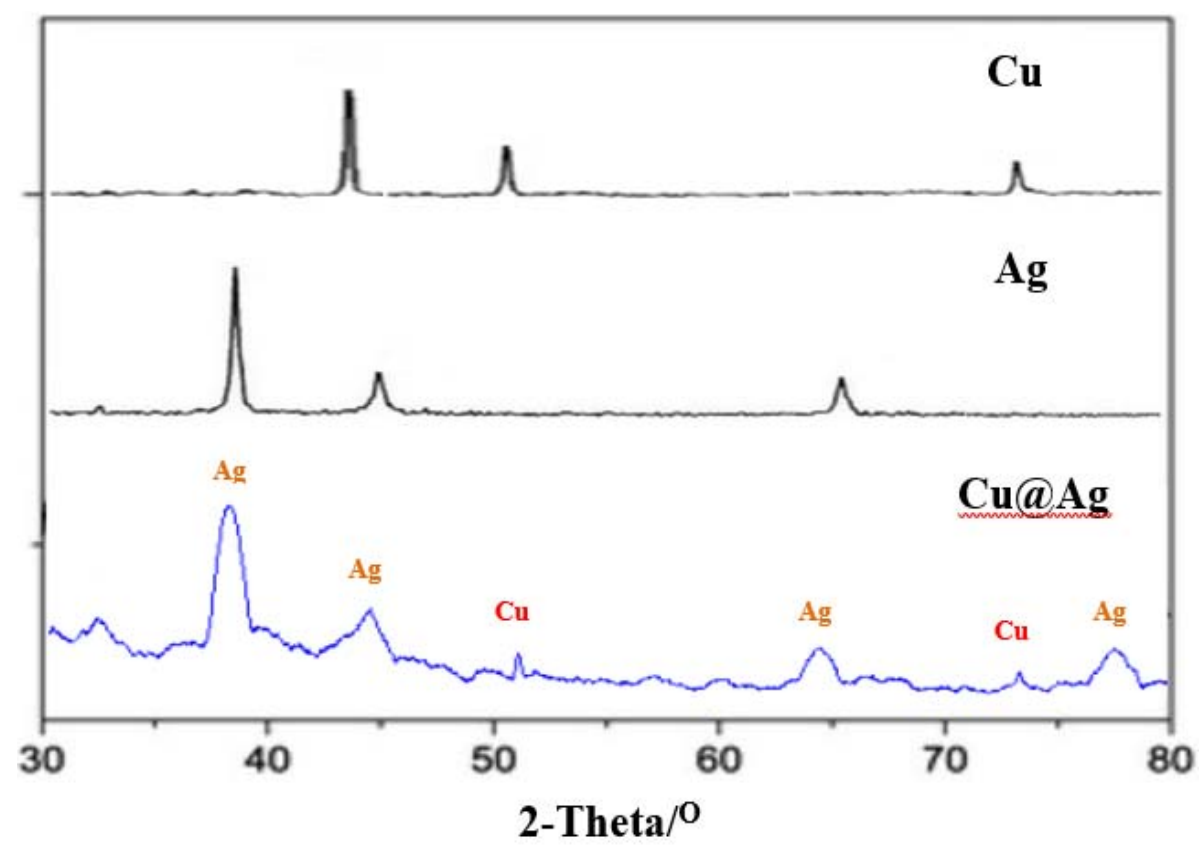

Fig. 7 XRD pattern of the Cu-Ag core-shell nanoparticles synthesized with $\mathbf{p H}=6$.

Fig. 6 shows that the sample was still stable after 80 days from synthesis. After 80 days from synthesis, the peak at the longer wavelength tends to decrease in intensity compared to that of other samples. In our previous studies, keeping $\mathrm{Cu}$ nanoparticles stable in a long time from synthesis was very difficult, because they were easily oxidized in solution. The results indicate that the reduction of the metal complexes $\left[\mathrm{Cu}\left(\mathrm{NH}_{3}\right)_{4}\right]^{2+}$ and $\left[\mathrm{Ag}\left(\mathrm{NH}_{3}\right)_{2}\right]^{+}$formed nanoparticles having better stability compared to the reduction of 
$\mathrm{Ag}^{+}$and $\mathrm{Cu}^{2+}$.

To evaluate the crystallization of the $\mathrm{Cu}-\mathrm{Ag}$ core-shell nanoparticles, we used the sample synthesized with $\mathrm{pH}=6$. The sample was centrifuged at $6,000 \mathrm{rpm}$ for 15 minutes followed by drying to obtain powder for XRD measurement. Fig. 7 shows the peaks corresponded to $\mathrm{Cu}$ and $\mathrm{Ag}$. The $\mathrm{Cu}$ nanoparticles are easily oxidized in solution under normal conditions. However, the XRD pattern of the sample shows no peaks of copper oxide $\mathrm{Cu}_{2} \mathrm{O}$. This indicates that the obtained $\mathrm{Cu}-\mathrm{Ag}$ core-shell nanoparticles had good structure and quality, because recent works of other research groups on the synthesis of $\mathrm{Cu}-\mathrm{Ag}$ core-shell nanoparticles reported that the XRD patterns of their samples still exhibited peaks of $\mathrm{Cu}_{2} \mathrm{O}[7,11-13]$. The results show that the $\mathrm{Cu}-\mathrm{Ag}$ core-shell nanoparticles synthesized with $\mathrm{pH}=6$ were stable under normal conditions without being oxidized. The obtained core-shell nanoparticles possessed suitable properties for using as conductive particles in fabrication of inks for ink-jet printing.

\section{Conclusions}

We have successfully synthesized the $\mathrm{Cu}-\mathrm{Ag}$ core-shell bimetallic nanoparticles using chemical reduction method. The results of XRD, TEM, and UV-Vis show that the obtained nanoparticles had a core-shell structure with average particle size of around $32 \mathrm{~nm}$. The results indicate that ratio of $\mathrm{Ag}^{+} / \mathrm{Cu}^{2+}=0.4$ and $\mathrm{pH}=6$ were the optimum conditions for the formation and stability of the nanoparticles. The nanoparticles dispersed stably after 80 days from synthesis under normal conditions without being oxidized. The properties of the obtained nanoparticles were suitable for use as conductive particles in fabrication of conductive inks for ink-jet printing.

\section{Acknowledgments}

The authors highly appreciate the financial support of FIRST Central Project Management Unit Grant
Agreement. This research is funded by FIRST Central Project Management Unit Grant Agreement No.: 09/FIRST/2a/INT.

\section{References}

[1] Chinh, D. T., Dung M. T. D., Thanh N. T. L., Thuy T. L., and Chien M. D. 2013. "Synthesis and Stability Control of Silver Nanoparticles Prepared by Using Glucose as Capping Agent in Chemical Reduction Method." Proceedings of IWNA 2013, Vung Tau, Vietnam 4: 608-13.

[2] Chien-Liang, L., Kun-Chuan, C., and Ciou-Mei, S. 2011. "Silver Nanoplates as Inkjet Ink Particles for Metallization at a Low Baking Temperature of $100{ }^{\circ} \mathrm{C}$." Physicochem. Eng. 381: 85-91.

[3] Steven, K., Volkman, Y. P., David, R., Shong, Y., and Vivek, S. 2004. "Ink-Jetted Silver/Copper Conductors for Printed RFID Applications." Mat. Res. Soc. Symp. Proc 814: 1781-6.

[4] Jianguo, L., Xiangyou, L., and Xiaoyan, Z. 2010. "Silver Nanoparticles Prepared by Chemical Reduction-Protection Method, and Their Application in Electrically Conductive Silver Nanopaste." Journal of Alloys and Compounds 494: 84-7.

[5] Jianhui, Z., Huaiyong, L., Zhenlin, W., and Naiben, M. 2007. "Preparation and Optical Properties of silica@Ag-Cu Alloy Core-Shell Composite Colloids." Journal of Solid State Chemistry 180: 1291-7.

[6] Kuan-Ting, C., Dahtong, R., Yu-hsien, P., and Yu-Chi, H. 2013. "Preparation of $\mathrm{Cu} @ \mathrm{Ag}$ Coreeshell Particles with Their Anti-oxidation and Antibacterial Properties." Current Applied Physics 13: 1496-501.

[7] Jun, Z., Dongming, Z., and Jie, Z. 2011. "Fabrication of $\mathrm{Cu}-\mathrm{Ag}$ Core-Shell Bimetallic Superfine Powders by Eco-Friendly Reagents and Structures Characterization." Journal of Solid State Chemistry 184: 2339-44.

[8] Jung-Pil, L., Dongchang, C., Mostafa, A. El-S., Soojin, P., Xiaxi, L., Seungmin, Y., Meilin, L., and Lawrence, A. B. 2013. "Well-Organized Raspberry-Like Ag@Cu Bimetal Nanoparticles for Highly Reliable and Reproducible Surface-Enhanced Raman Scattering." Nanoscale 5: 11620.

[9] Tsai, C. H., Chen, S. Y., Song, J. M., Chen, I. G., and Lee, H. Y. 2013, “Thermal Stability of Cu@Ag Core-Shell Nanoparticles." Corrosion Science 74: 123-9

[10] Nguyễn, Đ. N. 2007. Hóa học Nano, Nhà xuất bản khoa học tự nhiên và công nghệ, Hà Nội.

[11] Masaharu, T., Sachie, H., Ryuichi, T., Mika, M., and Yoshiyuki, S. 2010. "Syntheses of $\mathrm{Ag} / \mathrm{Cu}$ Alloy and $\mathrm{Ag} / \mathrm{Cu}$ Alloy Core $\mathrm{Cu}$ Shell Nanoparticles Using a Polyol Method." Cryst Eng Comm 11: 3337-964. 

Electrohydrodynamic Printing Technique

[12] Xing, S., Tan, L. H., Chen, T., Yang, Y., Chen, H. 2009. "Facile Fabrication of Triple-Layer (Au@Ag)@Polypyrrole_ Core-Shell and $\left(\mathrm{Au} @ \mathrm{H}_{2} \mathrm{O}\right) @$ Polypyrrole Yolk-Shell Nanostructures."
Chem Commun 16: 1653-4.

[13] Lisiecki, I., Billoudet, F., and Pileni, M. P. 1996. "Control of the Shape and the Size of Copper Metallic Particles.” J. Phys. Chem. 100 (10): 4160-6. 